\title{
Video-assisted thoracoscopic surgery in the treatment of patients with bullous emphysema
}

This article was published in the following Dove Press journal:

International Journal of General Medicine

5 August 2010

Number of times this article has been viewed

\author{
Kuan-Chun Lin' \\ Shi-Ping Luh ${ }^{2,3}$ \\ 'Department of Thoracic Medicine, \\ Chia-Yi Hospital, ${ }^{2}$ Thoracic Surgery, \\ St Martin De Porres Hospital, \\ ${ }^{3}$ National Chiao-Tung University, \\ Taiwan, China
}

Purpose: Surgical operation for bullous emphysema is indicated for patients with symptoms related to the compression of giant bullae (usually $>30 \%$ of hemithorax) or other related complications, such as infection, rupture, or bleeding. Video-assisted thoracoscopic surgery (VATS) has been widely applied in the diagnosis and treatment of patients with intrathoracic diseases, including bullous emphysema.

Materials and methods: We retrospectively reviewed nine patients with symptomatic or complicated bullous emphysema, who were treated by bullectomy using VATS in the past two years. Eight males and one female were included, with ages ranging from 39 to 82 (median 62) years. Eight (89\%) were heavy smokers. Pulmonary function tests were performed preoperatively in only three patients because of their compromised condition on admission.

Results: Bullae resection and pleurodesis was performed using VATS in the eight patients. The operating time ranged from 35 to 75 (median 50) minutes. Two patients had minor postoperative complications (one prolonged air leak for more than seven days and one wound infection), which recovered with conservative treatment. The chest tube was successfully removed 5-14 days postoperatively. Either symptomatic relief or improved pulmonary function was noted in these patients postoperatively. One patient complained of intermittent dyspnea during follow-up, but the imaging study was essentially normal.

Conclusion: Bullectomy for patients with bullous emphysema can be performed safely and effectively using VATS. Additional pleurodesis or suturing reinforcement can prevent the complication of air leak.

Keywords: video-assisted thoracoscopic surgery, bullous emphysema, bullectomy

\section{Introduction}

Bullous emphysema is defined as an expansion of the alveolar space with a diameter more than $1 \mathrm{~cm}$ and a wall thickness less than $1 \mathrm{~mm}$. ${ }^{1,2}$ Surgical resection of bullous emphysema is indicated for patients with symptoms related to the compression of giant bullae (usually $>30 \%$ of hemithorax) or related complications, including infection, rupture, or bleeding. ${ }^{2}$ Improvements in exercise tolerance and respiratory reserve, as well as resolution of related complications, have been reported when these patients undergo surgical intervention. ${ }^{3,4}$ A wide variety of surgical procedures has been used, including intracavity drainage, bullae resection or plication, or lobectomy. ${ }^{5-8}$ These procedures, traditionally performed via an open approach, such as thoracotomy or sternotomy, ${ }^{7}$ has gradually been replaced by video-assisted thoracoscopic surgery (VATS), a minimally invasive approach. ${ }^{9,10}$ In this study, our experience in the management of patients with giant or complicated bullous emphysema using VATS is
Correspondence: Shi-Ping Luh No 565, Sec 2, Da-Ya Rd, Chia-Yi City, Taiwan

Tel +88652756000 extn 1003

Fax +88 652762905

Email luh57200I@yahoo.com.tw 
presented, as well as comparison with other reported series in the literature.

\section{Patients and methods}

From January 2008 to December 2009, nine patients with bullous emphysema and related symptoms (dyspnea, chest tightness) or complications (infection, bleeding, pneumothorax) were treated by bullectomy using VATS. There were eight males and one female, aged 39-82 (median 62) years. All but one 39-year-old male had a long-term history of heavy smoking (more than one pack per day for more than 20 years). All patients underwent a general (hemogram, liver and kidney function, blood sugar and electrolytes), respiratory (plain chest film and computed tomography, arterial blood gas analysis), and cardiac (electrocardiogram) preoperative assessment. However, only three patients completed their pulmonary function tests (PFTs) preoperatively, and the others were unfit for this evaluation (because of pneumothorax, noncompliance, or ventilator-dependency) on admission. Mixed moderate to severe obstructive and mild to moderate restrictive ventilatory defects were found in three patients. Seven patients (78\%) had significant respiratory insufficiency (dyspnea more than Hugh-Jones Grade III). ${ }^{11}$ Bullous emphysema was classified according to DeVries and Wolfe ${ }^{12}$ (Figure 1A-C). Single large (Group I) and multiple (Group II) bullae without underlying pulmonary disease were identified in three
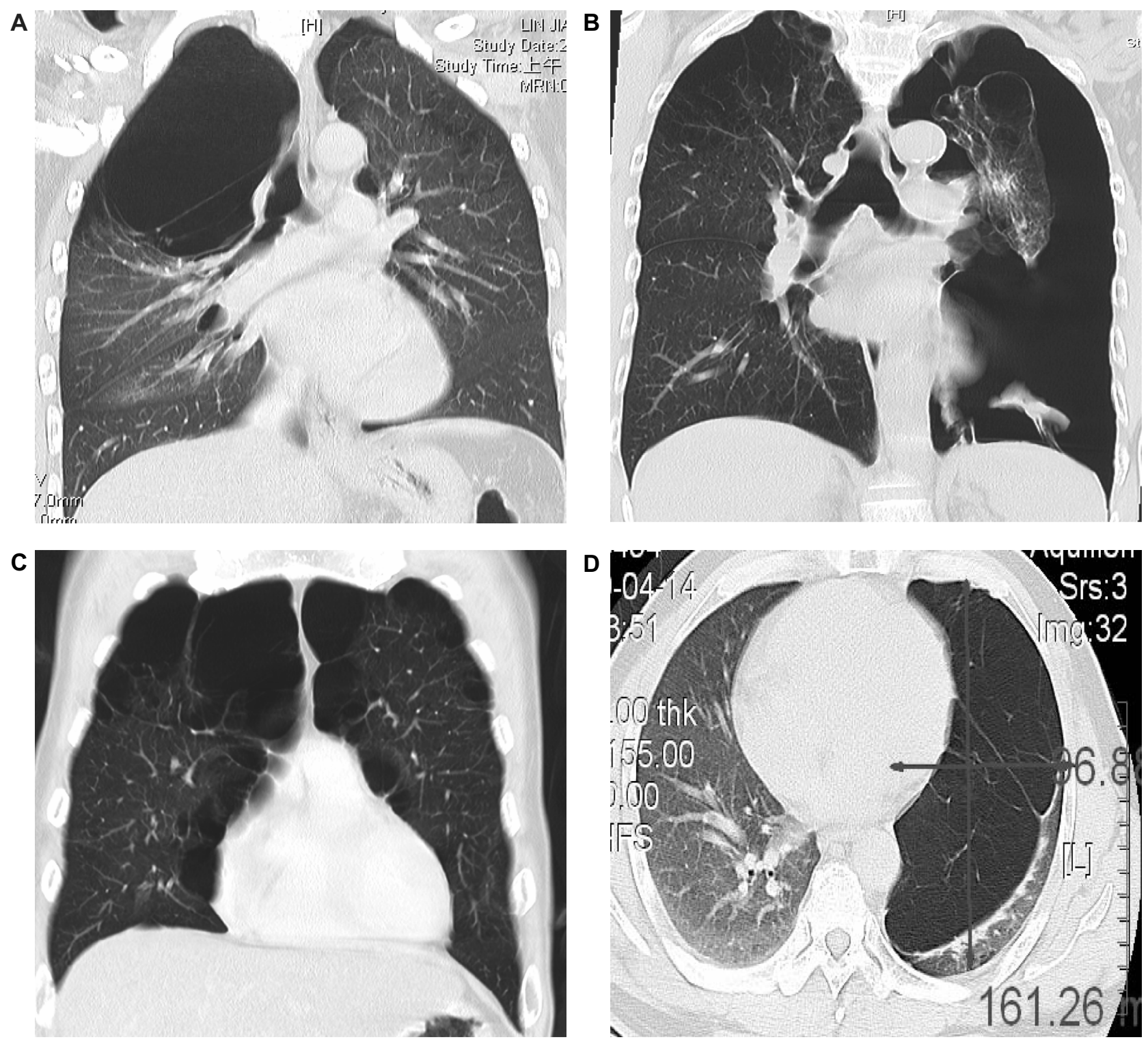

Figure I Computed tomography scan of various characteristics of bullous emphysema. A) Right single giant bullae with contralateral (left) blebs and pneumothorax. B) Bilateral bullae/blebs with left severe pneumothorax. C) Bilateral multiple bullae $\mathbf{D})$ Left tension giant bullae. 
and two of our patients, respectively. Bullae with underlying diffuse emphysema (Group III) or other lung diseases (Group IV) were identified in four patients and one patient, respectively. Locations of these bullae were on the right in four cases, on the left in three, and bilateral in two. Related complications were noted in six patients (67\%), comprising pneumothorax in four, uncontrolled hemoptysis in one, and pneumothorax with ventilator dependency in one patient. All of the patients were considered for surgery because symptoms or complications related to giant bullae had developed. The characteristics of these patients are listed in the Table 1.

VATS was performed with the patient under general anesthesia and double-lumen endotracheal intubation, and placed in the lateral decubitus position while leaving the operated side of lung unventilated. The first $10 \mathrm{~mm}$ port was placed in the prior tube thoracostomy wound or the fifth or sixth intercostal space in the middle or anterior axillary line. A $10 \mathrm{~mm}$ 30-degree end-viewing rigid telescope connected to the camera head and monitoring system was introduced into the thoracic cavity. Two additional working ports $(10-12 \mathrm{~mm})$ or one additional port along with one utility incision were fashioned in appropriate areas of the chest wall according to the location of the bullae or site of air leak. We could compress or puncture the bullae if they were too

Table I Patient characteristics, treatments and outcomes $(n=9)$

\begin{tabular}{|c|c|}
\hline Age (years), range (median) & $39-82(62)$ \\
\hline Male:Female & 8:1 \\
\hline Heavy smokers & $8(89 \%)$ \\
\hline Side left:right:bilateral & 4: 3: 2 \\
\hline $\begin{array}{l}\text { Classification of bullous emphysema } \\
(\mathrm{I}, \mathrm{II}, \mathrm{III}, \mathrm{IV})\end{array}$ & $3,2,4,1$ \\
\hline Dyspnea (Hugh-Jones) Grade I/II, III, IV, V & $2,3,3,1$ \\
\hline \multicolumn{2}{|l|}{ Pulmonary function test $(n=3)$} \\
\hline Moderate obstructive + mild restrictive & 2 \\
\hline Severe obstructive + moderate restrictive & I \\
\hline Associated preoperative complications & $6(67 \%)$ \\
\hline Pneumothorax & 4 \\
\hline Hemoptysis uncontrolled & I \\
\hline Pneumothorax + ventilator dependent & I \\
\hline VATS bullectomy + pleurodesis & 9 \\
\hline Bilateral procedures & $\mathrm{I}$ \\
\hline Mechanical pleurodesis & 9 \\
\hline Reinforcement by suturing (resection line) & 3 \\
\hline Additional partial pleurectomy & $\mathrm{I}$ \\
\hline Additional postoperative chemical pleurodesis & I \\
\hline Operating time (minutes, range, median) & $35-75(50)$ \\
\hline Duration of tube drainage (days, range, median) & $5-14(7)$ \\
\hline \multicolumn{2}{|l|}{ Complications $(n=2)$} \\
\hline Prolonged air leak ( $>7$ days) & I \\
\hline Wound infection & $\mathrm{I}$ \\
\hline Length of hospital stay (days) & $5-15(7)$ \\
\hline
\end{tabular}

Abbreviation: VATS, video-assisted thoracoscopic surgery. large to enable viewing of the thoracic cavity. Any adhesions between the bullae and chest wall or lung parenchyma were dissected to expose the base of the bullae. The walls of the bullae were then grasped with forceps and the lung parenchyma beneath the neck of bullae was cut and sutured using an endoscopic stapler without Peri-Strip ${ }^{\circledR}$ reinforcement (endo-GIA, 30, 45, or $60 \mathrm{~mm}$ in length, and 3.5 to $4.8 \mathrm{~mm}$ in thickness, Auto-Suture Company, United States Surgical Corporation, Norwalk, CT, Figure 2A-D). Mechanical pleurodesis with or without partial pleurectomy was used intraoperatively. The bullae resection lines were reinforced by continuous or interrupted suturing with 3-0 or 4-0 catgut or silk if air leak was detected after bullectomy. Chemical pleurodesis was administered by intrapleural instillation of four ampoules of tetracycline through the chest tube in event of prolonged air leak ( $>$ seven days) postoperatively. One or two French chest tubes size 28 to 32 were inserted into the pleural cavity after surgery, with continuous or intermittent low motor $\left(-10\right.$ to $\left.-15 \mathrm{~cm} \mathrm{H}_{2} \mathrm{O}\right)$ suction using the drainage bottle system. The chest tube could be removed when there was no more air leak, fluid drainage was less than $100 \mathrm{~mL} /$ day and light yellow or red in color, and the lung was fully re-expanded on chest radiograph after clamping the tube for 24 hours.

\section{Results}

The treatment methods and outcomes for our patients are shown in the Table. All nine patients underwent bullectomy and mechanical pleurodesis through VATS. Bilateral procedures were performed in one patient. Three patients required reinforcement of the resection line by suturing. Additional partial pleurectomy was performed in one patient to facilitate pleurodesis, due to minor leakage on the surface of the lung being noted intraoperatively. Utility incision (2.5-4 cm in length) was used, without applying a spreader, in three patients (33\%) for removal of larger resected bullae. No conversion to open thoracotomy was required in these patients. There was no mortality or major morbidity intra- or postoperatively. The operating time ranged from 35 to 75 (median 50) minutes. Prolonged air leak ( $>$ seven days) and wound infection was noted in one patient each, who recovered after conservative treatment. For the patient with ventilator dependency preoperatively, weaning from mechanical ventilation was performed successful. The chest tube(s) were successfully removed from 5-14 days postoperatively. The postoperative duration of hospital stay ranged from five to 15 (median seven) days. During a follow-up period of three months to two years, 

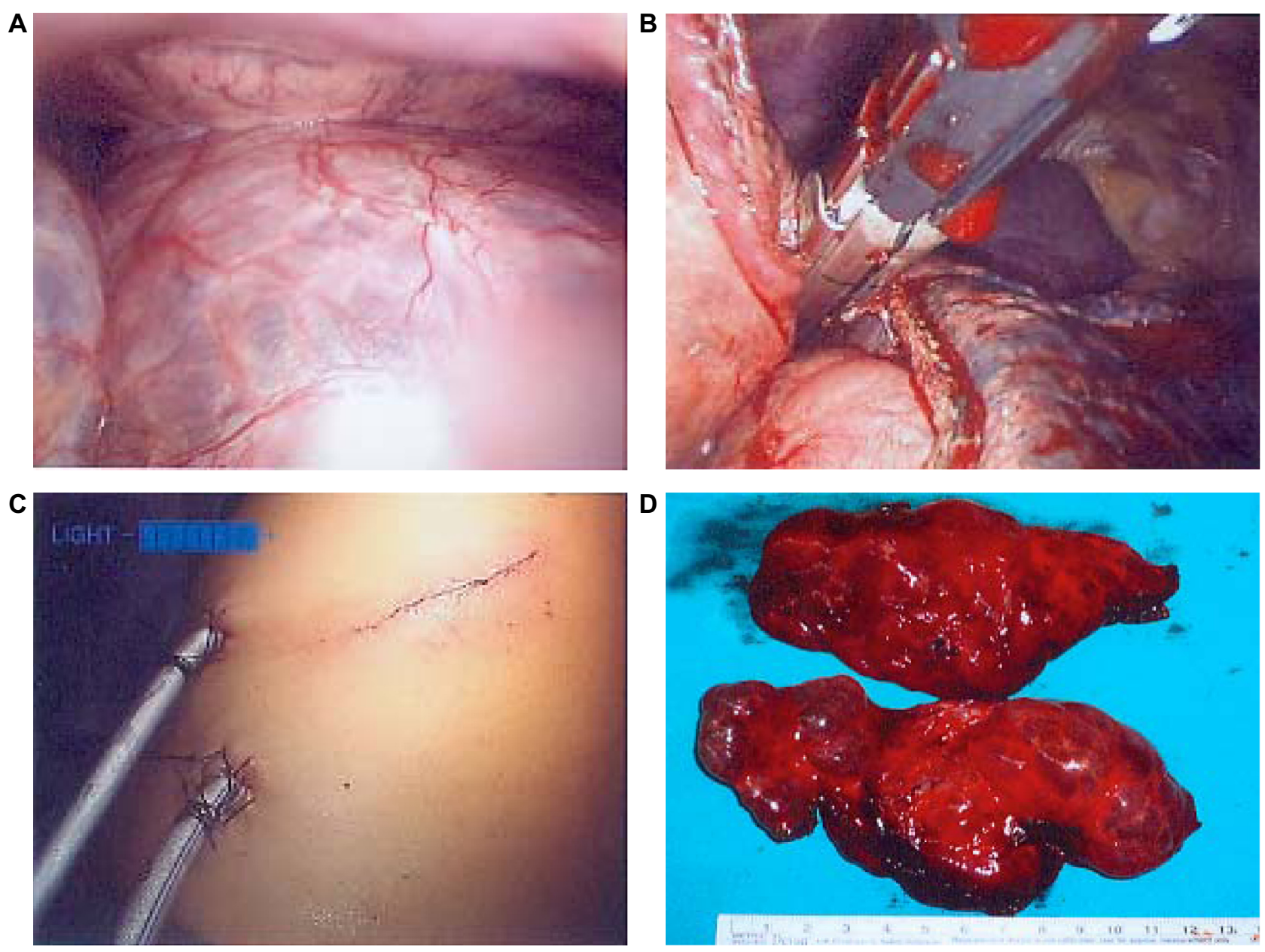

Figure 2 Video-assisted thoracoscopic surgery for patients with bullous emphysema. A) Giant bullae in the thoracic cavity; B) Endo-GIA stapling and resection; C) Operative wound and drainage; D) Resected bullae, gross picture.

eight $(89 \%)$ of the patients reported marked symptomatic relief and downstaging of the Sadou dyspnea index after treatment, and three patients with preoperative PFTs had marked improvement in $\mathrm{FEV}_{1}, \mathrm{FEV}_{1} / \mathrm{FVC}$ and $\mathrm{FVC}$ (more than $10 \%$ improvement) postoperatively. One patient complained of intermittent dyspnea during follow-up, but an imaging study was essentially normal.

\section{Discussion}

Various surgical procedures have been developed for the treatment of bullous emphysema since the 1930s, including plication, excision, resection, lobectomy, or even lung transplantation. ${ }^{13}$ Resection of bullae for patients with bullous emphysema is indicated if complications appear, such as pneumothorax, bleeding, or infection. ${ }^{2}$ Resection for patients with uncomplicated bullous emphysema is indicated when it is symptomatic, large in size (usually $>30 \%$ area of hemithorax), progressively growing in size, or functional in the adjacent compressed lung. ${ }^{13,14}$ The resec- tion of giant bullae could be viewed as a special case of lung volume reduction in emphysema. ${ }^{13,15}$ Hence removal of the bullae can re-expand the compressed functional lung to achieve better ventilation and gas exchange, as well as improve chest mechanics by remodeling of the thoracic cage and diaphragm., ${ }^{3,4,16,17}$ Surgical resection is contraindicated in patients with large bullae accompanied with hypercapnia or diffuse emphysema. Some alternative minimally invasive techniques, such as laser ablation, intracavity drainage, or introduction of OK-432 or fibrin glue into the cavity, can be used for these patients. These techniques have also been used in our group for limited cases. However, elevated risks of bronchopneumonia and prolonged air leak were still reported for these procedures. ${ }^{9,18,19}$

Resection of giant bullae was traditionally approached through open thoracotomy. The development of VATS in the 1990s has changed the timing and indication of surgical intervention for this disease, because it is minimally invasive and as effective as open procedures. ${ }^{9,10,13,14,17,20}$ Our results show that VATS is a safe, effective, and minimally invasive 
technique in the treatment of patients with symptomatic or complicated bullous emphysema.

Preoperative assessment is very important in the selection of VATS for patients with symptomatic or complicated bullous emphysema. Computed tomography of the chest can provide detailed information not only on location, size, and number of bullae, but also about adjacent pleural, mediastinal, and underlying pulmonary changes. ${ }^{9,21}$ Pulmonary function is also very important to assess prior to surgical intervention. Spirometry can be used to evaluate pulmonary ventilation volume-flow relationships. However, patients suffering from ruptured bullous emphysema with persistent air leak are unfit to undergo this assessment. Other evaluations, such as dyspnea index, diffusion capacity of carbon monoxide, blood gas analysis, six-minute walking test, or pulmonary perfusion-ventilation radionucleotide scanning can be used to assess pulmonary function. ${ }^{2,9-13}$ These parameters are crucial in selection of the surgical procedure as well as evaluation of clinical improvement following surgery.

Choice of VATS procedure for patients with bullous emphysema include endo-GIA stapling/resection, endoloop ligation, drainage, instillation of sclerosing agents, or fibrin glue into the bullae. ${ }^{5-8}$ Endo-GIA stapling/resection is our preferred method of bullae resection, and we only use endoloop ligation in a very small number of patients with primary spontaneous pneumothorax manifesting as multiple smaller blebs intraoperatively. ${ }^{22-24}$ Prolonged air leak from the bullae resection margins is the most common complication postoperatively for patients with bullous emphysema. ${ }^{9,12,25}$ Hence various methods have been developed to prevent this complication, including mechanical pleurodesis by abrasion, chemical instillation, or pleurectomy, ${ }^{2,9,10,26}$ or reinforcement of the resection line by suturing or Peri-Strip ${ }^{\circledR}$ wrapping..$^{25,27,28}$ In our practice, because too extensive pleurectomy might result in severe pain and significant hemorrhage, pleurodesis is performed by routine mechanical abrasion, with additional partial pleurectomy or chemical instillation in selective cases. A new method of pleurodesis, ie, low-energy argon plasma spray mode cauterization, has recently been developed by our group for selective cases. Peri-Strip reinforcement of the bullae resection line was used by our group several years ago. ${ }^{22,23}$ However, this is expensive so its use is limited clinically in our country. This problem has also been reported by Divisi et al, ${ }^{9}$ who used low-cost polytetrafluoroethylene as an alternative for suture line reinforcement. At present, we favor suturing only for reinforcement of the bullae resection line, and this procedure combined with pleurodesis can also prevent air leak and achieve satisfactory results.
In conclusion, bullectomy for patients with bullous emphysema can be safely and effectively performed using VATS. Pleurodesis with suturing over the resection-stapling edges for selective cases can prevent the complication of air leak.

\section{Disclosure}

The authors report no conflict of interest in this work.

\section{References}

1. Klingman RR, Angelillo VA, DeMeester TR. Cystic and bullous lung disease. Ann Thorac Surg. 1991;52(3):576-580.

2. Greenberg JA, Singhal S, Kaiser LR. Giant bullous lung disease: Evaluation, selection, techniques, and outcomes. Chest Surg Clin NAm. 2003;13(4):631-649.

3. Connolly JE, Wilson A. The current status of surgery for bullous emphysema. J Thorac Cardiovasc Surg. 1989;97(3):351-361.

4. Potgieter PD, Benatar SR, Hewitson RP, Ferguson AD. Surgical treatment of bullous lung disease. Thorax. 1981;36(12):885-890.

5. Venn GE, Williams PR, Goldstraw P. Intracavity drainage for bullous emphysematous lung disease: Experience with the Brompton technique. Thorax. 1988;43(12):998-1002.

6. Wesley JR, Macleod WM, Mullard KS. Evaluation and surgery of bullous emphysema. J Thorac Cardiovasc Surg. 1972;63(6):945-955.

7. Deslauriers J, Leblane F, McClish A. Bullous and bleb disease of the lung. In: Shields TW, editor. General Thorax Surgery. 3rd ed. Philadelphia, PA: Lea and Febiger; 1989.

8. Dartevelle P, Macchiarini P, Chapelier A. Operative technique of bullectomy. Chest Surg Clin N Am. 1995;5(4):735-749.

9. Divisi D, Battaglia C, Di Francescantonio W, Torresini G, Crisci R. Giant bullous emphysema resection by VATS. Analysis of laser and stapler techniques. Eur J Cardiothorac Surg. 2002;22(6):990-994.

10. Utsumi T, Akashi A, Funaki S. Novel method of thoracoscopic surgery for giant bulla without residual cavity. Asian Cardiovasc Thorac Ann. 2007;15(6):511-514.

11. Hugh-Jones P, Lambert AV. A simple standard exercise test and its use for measuring exertion dyspnoea. BMJ. 1952;1(4749):65-71.

12. DeVries WC, Wolfe WG. The management of spontaneous pneumothorax and bullous emphysema. Surg Clin North Am. 1980;60(4):851-866.

13. Menconi GF, Melfi FM, Mussi A, Palla A, Ambrogi MC, Angeletti CA. Treatment by VATS of giant bullous emphysema: Results. Eur $J$ Cardiothorac Surg. 1998;13(1):66-70.

14. Ishida T, Kohdono S, Fukuyama Y, et al. Video-assisted thoracoscopic surgery of bullous and bleb disorders of the lung using endoscopic stapling device. Surg Laparosc Endosc. 1995;5(5):349-353.

15. Snider GL. Reduction pneumoplasty for giant bullous emphysema Implications for surgical treatment of nonbullous emphysema. Chest. 1996;109(2):540-548.

16. Nakahara K, Nakaoka K, Ohno K, et al. Functional indications for bullectomy of giant bulla. Ann Thorac Surg. 1983;35(5):480-487.

17. De Giacomo T, Venuta F, Rendina EA, et al. Video-assisted thoracoscopic treatment of giant bullae associated with emphysema. Eur $J$ Cardiothorac Surg. 1999;15(6):753-6; discussion 756-757.

18. Macarthur AM, Fountain SW. Intracavity suction and drainage in the treatment of emphysematous bullae. Thorax. 1977;32(6):668-672.

19. Uyama T, Monden Y, Harada K, Kimura S, Taniki T. Drainage of giant bulla with balloon catheter using chemical irritant and fibrin glue. Chest. 1988;94(6):1289-1290.

20. Luh SP, Liu HP. Video-assisted thoracic surgery - the past, present status and the future. J Zhejiang Univ Sci B. 2006;7(2):118-128.

21. Simek J, Resl M, Kral B. Surgery for bullous emphysema. Acta Medica (Hradec Kralove). 1999;42(3):111-114.

22. Luh SP, Lee YC, Lee JM, Lee CJ. Videothoracoscopic treatment of spontaneous pneumothorax. Int Surg. 1996;81(4):336-338. 
23. Luh SP, Tsai TP, Chou MC, Yang PC, Lee CJ. Video-assisted thoracic surgery for spontaneous pneumothorax: Outcome of 189 cases. Int Surg. 2004;89(4):185-189.

24. Luh SP, Tsao TC. Video-assisted thoracic surgery for spontaneous haemopneumothorax. Respirology. 2007;12(3):443-447.

25. Yamaguchi A, Shinonaga M, Tatebe S, Souma T, Tsuchida M, Saito A. Thoracoscopic stapled bullectomy supported by suturing. Ann Thorac Surg. 1993;56(3):691-693.

26. Gaensler EA. Parietal pleurectomy for recurrent spontaneous pneumothorax. Surg Gynecol Obstet. 1956;102(3):293-308.
27. Juettner FM, Kohek P, Pinter H, Klepp G, Friehs G. Reinforced staple line in severely emphysematous lungs. J Thorac Cardiovasc Surg. 1989;97(3):362-363.

28. Cooper JD. Technique to reduce air leaks after resection of emphysematous lung. Ann Thorac Surg. 1994;57(4):1038-1039.

\section{Publish your work in this journal}

The International Journal of General Medicine is an international, peer-reviewed open-access journal that focuses on general and internal medicine, pathogenesis, epidemiology, diagnosis, monitoring and treatment protocols. The journal is characterized by the rapid reporting of reviews, original research and clinical studies across all disease areas.
A key focus is the elucidation of disease processes and management protocols resulting in improved outcomes for the patient.The manuscript management system is completely online and includes a very quick and fair peer-review system. Visit http://www.dovepress.com/ testimonials.php to read real quotes from published authors.

Submit your manuscript here: http://www.dovepress.com/international-journal-of-general-medicine-journal 